this plan does not answer very satisfactorily, for, independently of the escape of the fluid from the edges of the cell, a few of the largest crystals grow still larger at the expense of the smaller ones, and the beauty of the specimen is destroyed. The different forms of these crystals, as they appear in the microscope, are given in the Illustrations of Urine, Urinary Deposits, and Calculi. (Urine, plates I to IX.) See also The Microscope in its Application to Practical MIedicine, chapter ix, page 292 .

[To be continued.]

\section{OAtrinal Communications.}

\section{WARTY VEGETATIONS NEAR THE ANUS, AND THEIR TREATMENT. \\ By Tromas T. Griffith, Esq., Wrexham.}

Is a clinical lecture by M. Nélaton, reported in the Journal de IÍtlecine et de Chirurgic Pratiques for February last, he relates the case of a girl about 14 years of age, who was the subject of a very extensive growth of warty vegetations, seated partly within the anal orifice and partly around it, and attached to the skin by a membranous connexion. Its surface was granular, crackel, and secreted a sero-sanguinolent fluid. The anus seemed lost in the enormous cauliflower-looking mass, but still it retained its normal diameter. The disease might have been supposed to be syphilitic; but, after a careful consideration of all the special circumstances of the case, M. Nélaton decided against such an opinion; he also expressed doubts as to the disease commonly having such an origin. He had often seen patients labouring under it who had had no venereal taint, and others who never had had sexual intercourse; though he believes that patients actually syphilitic, or those frequently liable to it, are more likely to become the subjects of this morbid growth than others. He viewed it as an accident purely local, resulting from varied and combined causes. $\mathrm{He}$ advises caution in receiving the patient's own statements, and thinks it best to give a decided opinion only when it can be based on authentic facts. His treatment is entirely local. His patient was chloroformed, and the mass was removed by a ligature of annealed iron drawn so tight as to act as an écraseur. The raw surfaces were painted with perchloruret of iron, which acted as a styptic; and mild cauterisation, etc. For a few days afterwards, the parts were bathed with camphorated spirits. The cure was speedy and complete, and no fears of the return of the disease were felt.

My object in giving an abridged account of this case is to in. troduce one similar to it in its leading particulars.

CASE. Mr. J., aged 35, married, of good general health, about two years ago was aware of small warty growths near the anus, which gradually increased, extending along the opposed surfaces of the nates. 'They acquired in time a considerable size, and were occasionally sharply painful and inconvenient. Little or no discharge formed on the surface.

I saw the patient in January last, and advised the removal of the mass, which now occupied a space of about six square inches. The anus could only be discovered by the forcible separation of the nates. The growth seemed to consist of warty vegetations, each of which had its own independent root in the skin; but, as they grew close and parallel to each other, they formed masses most like the cauliflower, with granular cracked surfaces of a brownish colour. They showed no disposition to bleed on being touched, though doing this caused exquisite pain, which, I believe, arose from sensitiveness in the subjacent skin, and not from the growth itself.

The patient was placed as for lithotomy, and I removed, partly with a scalpel, but more readily with strong scissors curved on the flat, nearly the whole mass, when the patient felt very ill; and as he became rather faint, and the bleeding was free, I left a portion immediately around the anus, and stopped the bleeding by the free use of tincture of sesquichloride of iron. It, however, returned to some extent in the night. The next day, the patient was comparatively well, walked out, and in a few days resumed his professional duties. The portions that remained were, after a few months, entirely removed, and the patient was at once restored to a state of ease and comfort that he had not felt for a length of time.
The skin operated on very rapidly regained its usual healthy state and appearance.

In this case, there were no grounds for suspecting any $\vec{F}$ specific taint, as the patient never had syphilis or gonorrhœa in $\stackrel{f}{9}$ any form.

[It may not be generally known that caustic marks on the $\frac{\bar{\sigma}}{\bar{\sigma}}$ hands, of some days standing, may be removed by a strong solution of iodide of potassium rubbed well over the surface; $\mathbb{\mathbb { D }}$ and, by applying afterwards a little liquor potassæ, the skin is restored to its usual soft smooth state.]

\section{A N O B S C U R E C A S E.}

By W. Sankey, Esq., Dover.

Wr. Henry Bew, aged 13 years, applied to me on the 4 th September 1860 , with the following symptoms : excessive weakness, emaciation, constant thirst, feeble pulse, coated tongue, and dry hands. He complained of no pain. His mother stated. that from his birth he had been healthy and strong, and fond. of active pursuits; but that within the last three weeks he bade rapidly lost flesh and strength. On inquiry, I found that he passed a large quantity of limpid urine, and wetted his bed every night.

I prescribed three grains of hydrargyrum cum cretâ with two윽 grains and a half of Dover's powder at night, and a mixture of nitric and hydrochloric acids with quinine thrice daily. IN requested to have some of his urine for analysis at his nextes visit.

September 7th. I received a message to visit him on that or the following day, as he seemed much worse. About nine in 3 the evening, a second message came; and I lost no time in going to see him at about three miles distance.

On my arrival, I found him rapidly sinking. The extremities were cold; the pulse was scarcely perceptible; he was per-o fectly conscious, complaining of nothing but thirst. Death dide not take place till eight hours afterwards. I applied for permission to make a post morten examination, but did not obtaino it. Leave was given to pass a catheter with a view to obtain some urine for analysis; but the bladder was found empty.

\section{Cxamsactions of 退xamethes.}

\section{CAMBRIDGE AND FIUNTINGDON BRANCH.}

$\triangle$ CASE OF EPILEPSY, WITH SOME UNCOMMON SYMPTOMS AND A COMMENTARY THEREON.

By G. E. Paget, M.D., F.R.C.P., Cambridge. [Read at Cambridge, July 10th, 1860.]

IT is well known that the convulsive phenomena of epileptio fits differ more or less in different patients, and that the same patient is not unfrequently subject to attacks of two kinds difo fering in some respects, generally in the degree of their vioN lence. It is unnecessary for me to dilate on this fact, or describe any of the more frequent deviations from the normag type; but in the case I am about to relate, and in which the attacks are of two different kinds, the minor attacks are ex ceedingly peculiar. They assume a form which I never befores witnessed, and which is, I believe, in the highest degree rare. श

D. C. an agricultural labourer, residing with his parents at Meldreth, aged 20, and unmarried, was admitted an in-patien at Addenbrooke's Hospital, on July 2nd, 1856. From that time until August 1858, he was almost continuously under observation, either as in- or out-patient. At first, he was under the care of Dr. Bond; afterwards, for a long period, under m care; and for a short time under that of Dr. Fisher. My notes of his case extend, in detail, with few interruptions, over tw years; and on the 16th of last month, he was again (after $\mathbb{Q}$ long interval) admitted to the Hospital, and is at the presen time one of its inmates.

He had (and has) much of the ordinary appearance of as agricultural labourer: a robust figure, a head not ill shape but the occiput and nucha are large, and his forehead look heavier than it did in 1856. His features are regular, but have a dullish grave cast. His intelligence is of an ordinary kind, 